\title{
FAKTOR-FAKTOR YANG BERHUBUNGAN DENGAN KEHAMILAN TIDAK DIINGINKAN DI INDONESIA
}

\author{
The Factors Related To The Unwanted Pregnancy In Indonesia \\ Kirana Anggraini' ${ }^{\text {, Raditya Wratsangka }}{ }^{2}$, Krisnawati Bantas ${ }^{3}$, Sandra Fikawati ${ }^{4}$ \\ 1Departemen Obstetrik dan Ginekologi, Fakultas Kedokteran, Universitas Trisakti \\ 2 Departemen Obstetrik dan Ginekologi, Fakultas Kedokteran, Universitas Trisakti \\ ${ }^{3}$ Departemen Epidemiologi, Fakultas Kesehatan Masyarakat, Universitas Indonesia \\ ${ }^{4}$ Departemen Ilmu Gizi, Fakultas Kesehatan Masyarakat, Universitas Indonesia \\ Email: kirana_anggraeni@trisakti.ac.id
}

\begin{abstract}
ABSTRAK
Kehamilan tidak diinginkan merupakan masalah global, dan menyumbang 700.000 kematian ibu setiap tahunnya. Penelitian ini bertujuan untuk mengetahui faktor-faktor yang berhubungan dengan kehamilan tidak diinginkan di Indonesia. Desain studi adalah potong lintang, dengan responden sebanyak 13.955 perempuan berusia 15-49 tahun, yang melahirkan anak terakhir dalam 5 tahun sebelum survei. Penelitian ini menggunakan data sekunder, dari Survei Demografi Kesehatan Indonesia (SDKI) tahun 2012. Uji analisis yang digunakan adalah uji kai kuadrat (bivariat) dan regresi logistik ganda (multivariat). Hasil studi menunjukkan prevalensi ibu yang mengalami kehamilan tidak diinginkan di Indonesia sebanyak 8\%, dengan prevalensi tertinggi terdapat di provinsi Sulawesi Tengah $(11,9 \%)$ dan terendah di Papua (2.9\%). Pada analisis bivariat didapatkan hubungan yang bermakna antara tingkat ekonomi, tingkat pendidikan, wilayah tempat tinggal, status pernikahan, paritas, jarak kelahiran, usia dengan kehamilan tidak diinginkan dengan nilai $\mathrm{p}<0,25$. Pada analisis multivariat, variabel status pernikahan berhubungan signifikan dengan kehamilan tidak diinginkan setelah dikontrol dengan variabel tingkat ekonomi, tingkat pendidikan, wilayah tempat tinggal, paritas, jarak kelahiran dan usia. Disimpulkan faktor status pernikahan merupakan faktor paling dominan yang berhubungan dengan kehamilan tidak diinginkan. Penemuan ini diharapkan dapat menjadi masukan bagi pemerintah untuk meningkatkan pengetahuan dan partisipasi masyarakat tentang program Keluarga Berencana.
\end{abstract}

Kata Kunci : Perempuan, kunjungan K4, kehamilan tidak diinginkan

\section{ABSTRACT}

Unwanted pregnancy has become global problem which contributing to 700.000 mothers' mortalities every year. This research aims to discover factors related to the unwanted pregnancy in Indonesia. The study applies cross sectional design to 13.955 women age between 15 to 49 years giving birth to the last child 5 years prior to the survey. Moreover, this study uses secondary data of 2012 Indonesia Demographic Health Survey (IDHS). Analysis test implemented is bivariat and multivariate. The study outcome illustrates the prevalence of $8 \%$ mothers experiencing unwanted pregnancy in Indonesia, the highest percentage is in Central Sulawesi province (11,9\%) whereas the lowest is in Papua (2.9\%). The bivariat analysis shows a significant relation among economic level, education level, residential area, marital status, parity, birth spacing, age and the unwanted pregnancy at value of $p<0,25$. In contract, multivariate analysis describes that marital status has a significant relation to the unwanted pregnancy after controlled by variabel of economic level, education level, region of residence, parity, birth spacing and age. It is concluded that marital status factor is the most dominant factor relates to the unwanted pregnancy. This finding is expected to serve as government input to elevate knowledge and people's participation in Family Planning Program.

Keywords : Woman, K4 visit, unwanted pregnancy

\begin{tabular}{lll}
\hline Sekretariat & \multicolumn{2}{l}{ Article History: } \\
Editorial: Kampus FKM UNISMUH PALU - Palu 94118, & $\Rightarrow \quad$ Received 19 April 2018 \\
$\quad$ Sulawesi Tengah, Indonesia & $\Rightarrow \quad$ Revised 3 Mei 2018 \\
Telp/HP: +6281245936241, Fax (0451) 425627 & $\Rightarrow \quad$ Accepted 23 Mei 2018 \\
E-mail: jurnal.mppki@gmail.com & $\Rightarrow$ & Available online 25 Juni 2018 \\
OJS: http://jurnal.unismuhpalu.ac.id/index.php/PJKM &
\end{tabular}




\section{PENDAHULUAN}

Setiap tahun di seluruh dunia terdapat jutaan perempuan yang mengalami kehamilan. Kehamilan tersebut dapat terjadi pada perempuan dengan berbagai niat kehamilan. Berdasarkan niat kehamilan tersebut, maka kehamilan dapat dibedakan menjadi 3, yaitu kehamilan yang diinginkan, kehamilan yang tidak direncanakan, dan kehamilan yang tidak diinginkan. Kehamilan disebut diinginkan (wanted), apabila kehamilan terjadi pada suami istri yang ingin memiliki anak lagi. Kehamilan disebut tidak direncanakan (mistimed), apabila kehamilan terjadi pada pasangan suami istri yang masih menginginkan kehamilan, namun kehamilan tersebut terjadi lebih cepat dari yang direncanakan. Kehamilan disebut tidak diinginkan (unwanted), apabila kehamilan terjadi pada pasangan suami istri yang sudah tidak menginginkan anak sama sekali (Erol, dkk., 2010).

Pada tahun 2008, terdapat 208 juta kehamilan di dunia. Sebesar 185 juta kehamilan diantaranya terjadi di negara berkembang, dan sebesar 86 juta (41\%) dari kehamilan di dunia merupakan kehamilan tidak diinginkan. Menurut penelitian, sebesar 33 juta dari kehamilan tidak diinginkan ini berakhir dengan kelahiran yang tidak direncanakan, abortus spontan (11 juta) dan aborsi (41 juta). Kehamilan tidak diinginkan di Negara maju (29\%) lebih tinggi dibandingkan di Negara berkembang (20\%) (Singh, dkk., 2010). Kehamilan tidak diinginkan juga menyebabkan 700,000 kematian ibu setiap tahunnya. Kematian akibat kehamilan tidak diinginkan ini sebagian besar disebabkan akibat tidakan aborsi yang dilakukan dengan tidak steril (64\%) dan sebagian kecil karena masalah saat hamil dan melahirkan (Bankole, dkk., 2006). Di Indonesia, berdasarkan Survei Demografi Kesehatan Indonesia tahun 2012, terdapat $86 \%$ kelahiran yang diinginkan, $7 \%$ kelahiran yang tidak direncanakan dan $7 \%$ kelahiran yang tidak diinginkan (BPS, dkk., 2012).

Berbagai penelitian menunjukkan bahwa perempuan dengan kehamilan yang tidak diinginkan cenderung lebih sedikit untuk melakukan pemeriksaan kehamilan, merokok pada trimester ketiga kehamilan, melahirkan anak dengan berat bayi lahir rendah, melahirkan bayi prematur, tidak menyusi bayinya, dan berisiko mengalami hasil kesehatan yang lebih buruk dibandingkan perempuan yang menginginkan kehamilannya (Erol, 2010., Goossens, 2016., Nurcahyati, 2013., Karacam, 2011., Shah, 2011., Orr, 2000). Bayi yang dilahirkan dari ibu yang tidak menginginkan kehamilannya memiliki hasil kesehatan yang lebih buruk dibandingkan bayi yang dilahirkan dari ibu dengan kehamilan yang tidak direncanakan atau kehamilan tidak diinginkan. Anak-anak yang dilahirkan dari ibu yang mengalami kehamilan tidak diinginkan berisiko mengalami gangguan psikososial dalam perkembangannya dan memiliki hasil kesehatan serta hasil pendidikan yang lebih buruk dibandingkankan dengan anak yang dilahirkan dari ibu dengan kehamilan yang tidak direncanakan maupun kehamilan yang diinginkan (Orr, dkk., 2000., Gipson, dkk., 2008). Negara negara yang memiliki tingkat kehamilan tidak diinginkan yang tinggi, akan memiliki masalah dalam ketersediaandan distribusi sumber daya nasional dibandingkan dengan negara dengan tingkat kehamilan tidak diinginkan yang rendah (Yazdkhasti, dkk., 2015). Studi lain menunjukkan bahwa kehamilan dan kelahiran yang tidak diinginkan dapat menurunkan partisipasi ibu dalam meningkatkan pendidikannya dan lebih berisiko sulit mendapatkan pekerjaan. Hal ini kedepannya dapat menyebabkan masalah ekonomi baik pada ibu dan anak (Brown, dkk., 1995).

Penelitian menunjukkan bahwa kehamilan tidak diinginkan dapat disebabkan oleh berbagai faktor antara lain faktor kemiskinan (tidak memiliki sumber daya yang memadai untuk membesarkan seorang anak), adanya stigma terhadap perempuan yang hamil diluar nikah, keinginan untuk tetap sekolah/bekerja, tidak adanya dukungan dari pasangan, rendahnya akses untuk mengikuti program keluarga berencana. Faktor-faktor lain yang berhubungan antara lain adanya penghentian penggunaan kontrasepsi karena masalah persediaan dan metode kontrasepsi, tidak menggunakan kontrasepsi karena khawatir dengan efek samping, rendanya pengetahuan tentang risiko kehamilan, tidak adanya dukungan dari pasangan terhadap penggunaan kontrasepsi, adanya kesulitan dalam mengakses layanan kontrasepsi, dan adanya perubahan-perubahan yang tak terdu- 
ga dalam kehidupan (misalnya perceraian, pengangguran, atau penyakit) (Singh, dkk., 2010, Goossens, dkk., 2016, Brown, dkk., 1995, Chandra, dkk., 2005, Prosannajid, 2009). Penelitian tentang faktor-faktor yang berhubungan dengan terjadinya kehamilan tidak diinginkan telah dilakukan dibeberapa negara, namun belum pernah dilakukan di Indonesia. Sehingga peneliti tertarik untuk mengetahui faktor-faktor yang berhubungan dengan kehamilan tidak diinginkan di Indonesia.

\section{METODE PENELITIAN}

Penelitian dengan desain potong lintang ini dilakukan terhadap 13.995 perempuan yang berusia 15-49 tahun yang hamil anak terakhir dan melahirkan anak baik hidup maupun meninggal dalam waktu 5 tahun sebelum survey. Responden penelitian ini berasal dari 33 propinsi di seluruh Indonesia. Penelitian ini dilakukan pada bulan Januari 2017, dengan menggunakan data sekunder dari Survei Demografi dan Kesehatan Indonesia (SDKI) tahun 2012. Prosedur dan kuesioner untuk survey ini telah ditinjau dan disetujui oleh ICF Institutional Review Board (IRB). ICF IRB memastikan bahwa survei mematuhi peraturan Departemen Kesehatan dan Pelayanan di Amerika Serikat untuk perlindungan subyek manusia (45 CFR 46), sementara IRB di negara tuan rumah memastikan bahwa survei sesuai dengan hukum dan normanorma bangsa. Sampel penelitian ini diambil dari seluruh responden yang memenuhi kriteria inklusi dan kriteria eksklusi (total sampling). Kriteri inklusi penelitian ini adalah seluruh perempuan berusia 15-49 tahun yang hamil anak terakhir dan melahirkan anak baik hidup maupun meninggal dalam waktu 5 tahun sebelum survei. Kriteria eksklusi penelitian ini adalah perempuan yang mengalami kehamilan yang tidak direncanakan.

Informasi tentang niat kehamilan, paritas, wilayah tempat tinggal, status pernikahan, tingkat pendidikan, tingkat ekonomi, jarak kelahiran dan usia responden dinilai dengan mengolah informasi dari kuesioner SDKI, 2012 dari daftar pertanyaan wanita no : 405, 406, 403, 5, 601, 602, 610, 105, 101-123, 217,103 . Analisis univariat digunakan untuk mengetahui distribusi frekuensi masingmasing variabel. Analisis bivariat menggunakan uji kai kuadrat dilakukan untuk mendapatkan kandidat yang akan masuk dalam analisis multivariat, dan analisis multivariat regresi logistik ganda model prediksi digunakan untuk mengetahui variabel independen yang paling dominan yang berhubungan dengan kehamilan tidak diinginkan.

\section{HASIL}

Hasil penelitian menunjukan prevalensi ibu yang mengalami kehamilan tidak diinginkan sebanyak 8\%. Prevalensi kehamilan tidak diinginkan di Indonesia yang tertinggi terdapat di provinsi Sulawesi Tengah $(11,9)$, Sulawesi Utara $(11,1)$ Jawa Barat $(10,9)$, dan Bangka Belitung $(10,9)$. Prevalensi kehamilan tidak diinginkan terendah terdapat di Papua (2.9), Kalimantan Barat (2.8), Nusa Tenggara Barat (2.9) (Lihat lampiran, tabel 1). Selain itu, terdapat 29.6 persen responden yang memiliki anak $>2,14.3$ persen responden memiliki anak dengan jarak lahir $<3$ tahun, 16.4 persen responden berusia $<20$ tahun dan 10.9 persen responden berusia $>35$ tahun. Pada variabel tingkat pendidikan, terdapat 60.2 persen reponden yang belum tamat SMA. Pada variabel tingkat ekonomi, terdapat 38 persen responden yang memiliki tingkat ekonomi miskin dan sangat miskin (Lihat lampiran, tabel 2).

Pada analisis bivariat didapatkan bahwa kehamilan tidak diinginkan terbanyak terjadi pada usia 40-49 tahun (36,9\%); paritas > 4 (26,5\%); tinggal di perkotaan $(8,9 \%)$, sudah menikah (7,9\%); tingkat ekonomi miskin (8,3\%); jarak lahir 13-24 bulan (13,3\%), 25-36 bulan (12,9\%) dan 112 bulan (12,2\%); dan tingkat pendidikan tidak tamat SD $(9,8 \%)$ (Lihat lampiran, tabel 3). Selain itu, hasil analisis bivariat menunjukkan bahwa tingkat ekonomi, tingkat pendidikan, jarak lahir, status pernikahan, wilayah tempat tinggal, paritas, dan usia responden berhubungan dengan signifikan dengan kehamilan tidak diinginkan dengan nilai $\mathrm{p}<0.25$ (Lihat lampiran, tabel 4). Pada analisis multivariat, status pernikahan adalah faktor yang paling dominan yang berhubungan dengan kehamilan tidak diinginkan setelah dikontrol oleh variabel konfounder. (Lihat lampiran, tabel 5). 


\section{PEMBAHASAN}

Pada tahun 2008, terdapat 208 juta kehamilan di dunia. Sebesar 185 juta kehamilan diantaranya terjadi di negara berkembang, dan sebesar 86 juta (41\%) dari kehamilan di dunia merupakan kehamilan tidak diinginkan. Kehamilan tidak diinginkan di Negara maju (29\%) lebih tinggi dibandingkan di Negara berkembang (20\%) (Singh, dkk., 2010). Kejadian kehamilan tidak diinginkan didunia, tertinggi terjadi di Asia (54\%), diikuti Afrika (22,5\%), Amerika Latin (11.8) dan Eropa (7,5\%). Dari berbagai kawasan di Asia, kawasan dengan kejadian kehamilan tidak diinginkan tertinggi adalah di Southcentral $(23,7 \%)$, diikuti Eastern (16,1\%), Southeastern $(9,8 \%)$ dan Western $(4,1 \%)$ (Sedgh, 2014). Di Indonesia, prevalensi kehamilan tidak diinginkan $(8 \%)$ lebih rendah dibandingkan prevalensi kehamilan tidak diinginkan di Asia Tenggara. Menurut kategori provinsi di Indonesia, masih terdapat 14 provinsi dengan kejadian kehamilan tidak diinginkan yang diatas angka nasional, yaitu provinsi Riau (10,1\%), Bengkulu (10,4\%), Bangka Belitung (10,9\%), Kepulauan Riau $(10,7 \%)$, Jakarta (8,2\%), Jawa Barat (10,9\%), Jawa Tengah $(9,8 \%)$, Yogyakarta $(10,7 \%)$, Kalimantan Timur (10,4\%) dan Sulawesi Utara $(11,1 \%)$, Sulawesi Tengah $(11,9 \%)$, Sulawesi Selatan (10,5\%), Gorontalo (8,6\%) dan Papua Barat $(8,1 \%)$.

Menurut program keluarga berencana, yang merupakan salah satu strategi untuk mengurangi kematian ibu, diharapakan ibu hamil tidak berada dalam kondisis 4T; yaitu terlalu muda melahirkan (di bawah usia 20 tahun), terlalu sering melahirkan, terlalu dekat jarak melahirkan (kurang dari 3 tahun), dan terlalu tua melahirkan (di atas usia 35 tahun). Selain untuk menurunkan dampak yang merugikan terhadap ibu dan bayi yang dikandungnya, program keluarga berencana ini juga bertujuan untuk meningkatkan kualitas keluarga sehingga timbul rasa aman, tentram, dan sejahtera.15 Pada penelitian ini, ternyata masih terdapat $29.6 \%$ responden yang memiliki anak $>2,14.3$ persen responden yang memiliki jarak lahir $<3$ tahun, 16.4\% responden berusia $<20$ tahun dan 10.9 responden berusia $>35$ tahun.

Pada penelitian ini didapatkan bah- wa sebagian besar responden pada penelitian memiliki status pernikahan sudah menikah (97,1\%), hanya sebagian kecil responden yang belum menikah $(2,9 \%)$. Pada hasil analisis bivariat didapatkan bahwa ibu yang sudah menikah secara signifikan akan lebih banyak mengalami kehamilan tidak diinginkan $(7,9 \%)$ dibandingkan ibu yang tidak menikah $(1,1 \%)$. Hal ini berbeda dengan hasil berbagai studi yang telah dilakukan dimana proporsi kehamilan yang tidak diinginkan lebih tinggi di kalangan perempuan yang belum menikah atau masih lajang dibandingkan dengan perempuan yang sudah menikah. (Goossens, dkk., 2016, Chandra, dkk., 2005, Henshaw, 1998, Finer, dkk.., 2006). Pada hasil analisis multivariat juga didapatkan bahwa status pernikahan merupakan variabel yang paling dominan, yang berhubungan dengan kehamilan tidak diinginkan. Kemungkinan ibu yang menikah yang mengalami kehamilan yang tidak diinginkan 4.5 kali dibandingkan ibu yang tidak menikah mengalami kehamilan tidak diinginkan. Menurut studi di negara berkembang, kehamilan tidak diinginkan pada pasangan yang sudah tidak menginginkan anak lagi dapat disebabkan karena kegagalan menggunakan alat kontrasepsi atau tidak menggunakan alat kontrasepsi (Erol, dkk., 2010, Yazdkhasti, dkk., 2015). Kegagalan penggunaan alat kontrasepsi lebih sering dijumpai pada jenis kontrasepsi pil dan suntik, yang dapat disebabkan karena ketidakteraturan pengguna dalam mengkonsumsi pil dan kedatangan pasien yang tidak sesuai jadwal dalam melakukan penyuntikan ulang. (Erol, dkk., 2010, Nurcahyani, dkk., 2013). Selain itu, efektifitas kontrasepsi suntik dan pil lebih rendah dibandingkan kontrasepsi jenis IUD, implan, vasektomi dan tubektomi. Terjadinya kegagalan pada penggunaan kontrasepsi suntik dan pil adalah 6-12 kehamilan setiap 100 perempuan dalam waktu 1 tahun. Sementara, terjadinya kegagalan penggunaan kontrasepsi jenis IUD, implan, vasektomi dan tubektomi adalah $<1$ kehamilan setiap 100 perempuan dalam waktu 1 tahun. Menurut data SDKI tahun 2012, pada peserta KB baru, yaitu Pasangan Usia Subur (PUS) yang baru pertama kali menggunakan alat/cara kontrasepsi dan atau pasangan usia subur yang kembali menggunakan metode kontrasepsi setelah melahirkan/keguguran, alat kontrasepsi tersering yang digunakan adalah sun- 
tik $(51,53 \%)$ dan pil $(23,17 \%)$ dibandingkan implan $(11,37)$ dan IUD $(7,23)$. Demikian juga halnya dengan peserta KB aktif, yaitu PUS yang saat ini menggunakan salah satu alat kontrasepsi tanpa diselingi kehamilan, alat kontrasepsi yang paling sering digunakan adalah suntik $(47,96 \%)$ dan pil $(22,81 \%)$ dibandingkan implan $(11,20 \%)$ dan IUD (10,61\%) (BPS, dkk., 2013). Menurut data dari Kementrian Kesehatan tahun 2016, saat ini terdapat 74,80\% perempuan di Indonesia yang sudah menggunakan suatu cara untk menunda ataupun menghentikan kehamilannya. Selain itu, kejadian kehamilan tidak diinginkan pada perempuan yang sudah menikah juga dapat disebabkan karena adanya PUS yang memutuskan untuk tidak memanfaatkan program keluarga berencana $(12,77 \%)$ yang disebabkan karena ingin menunda memiliki anak $(6,22 \%)$ maupun tidak ingin memiliki anak lagi $(6,55 \%)$. Kelompok PUS ini disebut sebagai unmet need. (BPS, dkk., 2013).

Menurut kelompok usia, kehamilan tidak diinginkan terbanyak terjadi pada usia 40-49 tahun $(36,9 \%)$. Hal ini berbeda dengan studi yang telah dilakukan sebelumnya, dimana kelompok remaja merupakan kelompok yang memiliki persentase tertinggi untuk mengalami kehamilan yang tidak diinginkan (Finer, dkk., 2006). Tingginya kejadian kehamilan tidak diinginkan pada kelompok usia 40-49 tahun ini dapat disebabkan karena mulai menurunnya persentasi penggunaan alat kontrasepsi pada usia ini. Hal ini dapat disebabkan adanya persepsi dikelompok tersebut bahwa perempuan yang sudah memasuki masa menopause memiliki kemungkinan yang lebih kecil untuk mengalami kehamilan (DBKKL, dkk., 2012). Hal ini juga didukung pada data SDKI tahun 2012, dimana mulai terjadi penurunan persentase penggunaan alat kontrasepsi modern dari 57,9\% pada usia 35-39 tahun menjadi $53,5 \%$ pada usia $40-44$ tahun, dan semakin menurun menjadi $36,3 \%$ pada usia 45-49 tahun ((BPS, dkk., 2013).

Menurut kelompok paritas, kehamilan tidak diinginkan terbanyak terjadi pada paritas $>4(26,5 \%)$. Hasil ini sesuai dengan studi lain bahwa terdapat hubungan antara paritas dengan kejadian kehamilan tidak diinginkan, dimana semakin tinggi paritas maka semakin tinggi risiko terjadinya kehamilan tidak diinginkan (Goossens, dkk., 2016, Gipson, dkk., 2008, Bitto, dkk., 1997). Pada laporan SDKI tahun 2012 juga didapatkan penurunan penggunaan kontrasepsi modern yaitu dari $61,0 \%$ pada perempuan dengan paritas 3-4 menjadi $43 \%$ pada paritas 5+ (BPS, dkk., 2013).

Menurut wilayah tempat tinggal, kehamilan tidak diinginkan terbanyak terjadi di perkotaan $(8,9 \%)$. Hal ini sesuai dengan penelitian yang dilakukan di Bangladesh, dimana kehamilan yang tidak diinginkan lebih tinggi pada perempuan yang tinggal di kota dibandingkan perempuan yang tinggal $\mathrm{di}$ desa (Prosannajid, 2009). Menurut laporan dari SDKI tahun 2012 juga didapatkan bahwa penggunaan kontrasepsi modern di perkotaan $(39,7 \%)$ lebih sedikit dibandingkan dengan di pedesaan $(46,0 \%)$ (BPS, dkk., 2013).

Menurut kelompok tingkat ekonomi, kehamilan tidak diinginkan terbanyak terjadi pada tingkat ekonomi miskin $(8,3 \%)$. Hal ini sesuai dengan studi yang telah dilakukan, bahwa kehamilan yang tidak diinginkan jauh lebih tinggi pada perempuan yang berada di bawah tingkat kemiskinan (Goossens, dkk., 2016, Gipson, dkk., 2008, Chandra, dkk., 2005, Prosannajid, 2009). Meskipun menurut laporan SDKI tahun 2012 tingkat penggunaan kontrasepsi modern pada tingkat ekonomi miskin ini yang tertinggi $(61,4 \%)$ dibandingkan tingkat ekonomi sangat miskin $(53,0 \%)$, pertengahan $(60,2 \%)$, kaya $(58,7 \%)$ dan sangat kaya $(55,4 \%)$. Namun trend penggunaan kontrasepsi pada tingkat ekonomi miskin ini masih didominasi dengan penggunaan jenis kontrasepsi suntik (36,9\%) dan pil $(14,4 \%)$ (BPS, dkk., 2013). Dimana kontrasepsi jenis suntik dan pil ini memiliki efektifitas yang lebih rendah dibandingkan kontrasepsi jenis IUD dan sterilisasi wanita (Kemenkes RI, 2016). Sedangkan pada tingkat ekonomi kaya, pertengahan dan sangat kaya, penggunaan kontrasepsi jenis IUD dan sterilisasi wanita lebih tinggi dibandingkan pada tingkat ekonomi miskin (BPS, dkk., 2013).

Menurut jarak lahir, kehamilan tidak diinginkan terbanyak terjadi pada jarak lahir $<36$ bulan $(38,4 \%)$. Diantara responden dengan jarak lahir < 36 bulan ini, distribusi terbesar terdapat pada jarak lahir 13-24 bu- 
lan $(13,3 \%)$ dibandingkan responden dengan jarak lahir 25-36 bulan (12,9\%) dan jarak lahir 1-12 bulan (12,2\%). Studi sebelumnya juga menunjukkan hal yang sama, dimana perempuan yang hamil dengan jarak kurang dari 18 bulan dengan kelahiran anak yang sebelumnya berhubungan dengan peningkatan risiko terjadinya kehamilan yang tidak diinginkan (Wind, 2013). Menurut kelompok tingkat pendidikan, kehamilan tidak diinginkan terbanyak terjadi pada tingkat pendidikan tidak tamat SD $(9,8 \%)$. Hal ini sesuai dengan penelitian sebelumnya dimana kehamilan tidak diinginkan terbanyak pada kelompok perempuan dengan pendidikan yang rendah.

\section{KESIMPULAN DAN SARAN}

Status pernikahan merupakan faktor paling dominan yang berhubungan dengan kehamilan tidak diinginkan setelah dikontrol dengan variabel tingkat ekonomi, tingkat pendidikan, wilayah tempat tinggal, paritas, jarak kelahiran dan usia. Kemungkinan ibu yang menikah untuk mengalami kehamilan yang tidak diinginkan 4.5 kali lebih besar dibandingkan ibu yang tidak menikah untuk mengalami kehamilan tidak diinginkan. Saran untuk tenaga kesehatan adalah untuk dapat memberikan konseling tentang penggunaan alat kontrasepsi pada setiap pasangan usia subur sejak dini, terutama setelah melahirkan agar setiap pasangan memiliki tingkat pengetahuan yang baik dalam merencanakan kehamilannya. Selain itu, konseling tentang cara menggunakan alat kontrasepsi dengan benar khususnya pada pilihan alat kontrasepsi jenis pil dan kondom harus dijelaskan sampai pasangan benarbenar mengerti sehingga resiko kehamilan akibat kegagalan penggunaan alat kontrasepsi tersebut dapat diturunkan.

\section{UCAPAN TERIMA KASIH}

Penulis mengucapkan terima kasih kepada USAID yang telah memberikan data untuk penelitian ini sehingga penelitian ini dapat dilakukan. Penulis juga mengucapkan terima kasih kepada Fakultas Kedokteran Universitas Trisakti yang telah terus menerus memberikan dukungannya mulai dari proses pengolahan data sampai publikasi penelitian.
DAFTAR PUSTAKA

Badan Pusat Statistik (BPS), [Indonesia], Badan Koordinasi Keluarga Berencana Nasional (BKKBN), Departemen Kesehatan, dan Macro Internasional. Survei Demografi dan Kesehatan Indonesia 2012. Calverton, Mayrland, USA: BPS dan Macro International.2013.

Bankole A et al, 2006. unwanted pregnancy and unsafe Abortion in Nigeria, cause and consequences. New York: Guttmacher Institute.

Bitto, A., R.H. Gray, J.L. Simpson, J.T. Queenan, R.T. Kambic, A. Perez, P. Mena, M. Barbato, C. Li,and V. Jennings. 1997. Adverse outcomes of planned and unplanned pregnancies among users of natural family planning: A prospective study. American Journal of Public Health. 87(3): 338-343.

Brown SS, Eisenberg L, editors. 1995. The Best Intentions: Unintended Pregnancy and the Well Being of Children and Families. Washington (DC): National Academies Press (US).Institute of Medicine (US) Committee on Unintended Pregnancy; 3, Consequences of Unintended Pregnancy. Available from: https://www.ncbi.nlm.nih.gov/books/ NBK232137/

Chandra, A., Martinez, G., Mosher, W. D., Abma, J., \& Jones, J. 2005. Fertility, family planning, and reproductive health of U.S. women: Data from the 2002 National Survei of Family Growth. Vital Health Statistics. 23(25).

Direktorat Bina Ketahanan Keluarga Lansia, Rentan Badan Kependudukan, Keluarga Berencana Nasional Jakarta. 2012. Pembinaan Kesehatan Reproduksi Bagi Lansia. Jakarta.

Erol N, Durusoy R, Ergin I, Döner B, Ciçeklioglu M. 2010. Unintended pregnancy and prenatal care: A study from a maternity hospital in Turkey. The European Journal of Contraception and Reproductive Health Care.;15(4):290-300. doi: 10.3109/13625187.2010.500424

Finer, L. B., Zolna, M. R. 2011. Unintended pregnancy in the United States: Incidence and disparities, 2006. Contraception. 84(5):478-485. 
Gipson, J. D., Koenig, M. A. and Hindin, M. J. 2008. The Effects of Unintended Pregnancy on Infant, Child, and Parental Health: A Review of the Literature. Studies in Family Planning, 39: 18-38. doi:10.1111/j.17284465.2008.00148.x

Goossens J, Branden YVD, Sluys LVd, Delbaere I, Hecke AV, Verhaeghe $S$, et al. The prevalence of unplanned pregnancy ending in birth, associated factors, and health outcomes. Hum Reprod. 2016;31(12):2821-33. doi: 10.1093/ humrep/dew266

Henshaw SK. 1998. Unintended pregnancy in the United States, Family Planning Perspectives. 30(1):24-29 \& 46.

Karacam Z, Onel K, Gercek E. 2011. Effects of unplanned pregnancy on maternal health in Turkey. Midwifery, 27(2): 288-93.

Kementrian Kesehatan Republik Indonesia. 2016. Health Statistisc.

Nurcahyani, D., \& Trihandini, I. 2013. Kehamilan yang Tidak Diinginkan dan Berat Badan Lahir Bayi. Kesmas: National Public Health Journal, 7(8), 354359. doi:http://dx.doi.org/10.21109/ kesmas.v7i8.21

Orr ST et al. 2000. Unintended pregnancy and preterm birth. Paediatric Perinatal Epidemiology. 14: 309-313.

Prosannajid Sarkar. 2009. Unintended Pregnancies in Bangladesh: Levels and Correlates. Journal of Modern Mathematics and Statistics. 3: 78-81.

Sedgh. 2014. Intended and unintended pregnancies worldwide in 2012 and recent trend. Studies in Family Planning. 45 [3]:301-314.

Shah, P.S., Balkhair, T., Ohlsson, A. et al. Matern Child Health J. 2011. 15: 205. https://doi.org/10.1007/s10995-0090546-2.

Singh S, Sedgh G, Hussain R. 2010. Unintended pregnancy: worldwide levels, trends, and outcomes. Stud Fam Plann, 41(4):241-50.

Wind, Rebecca. 2013. Preventing unintended pregnancies could reduce short spacing between pregnancies, improving maternal and newborn health. https:// guttmacher.org/media/ nr/2013/06/07/index.html
Yazdkhasti M, Pourreza A, Pirak A, Abdi F. 2015. Unintended pregnancy and its adverse social and economic consequences on health system: A narrative review article. Iran J Public Health. 44:12-21. 
LAMPIRAN

Tabel 1. Prevalensi Kehamilan Tidak Diinginkan Menurut Provinsi di Indonesia

\begin{tabular}{|c|c|}
\hline Provinsi & Kehamilan Tidak Diinginkan (\%) \\
\hline Aceh & 4.3 \\
\hline Sumatera Utara & 7.2 \\
\hline Sumatera Barat & 8.0 \\
\hline Riau & 10.1 \\
\hline Jambi & 6.7 \\
\hline Sumatera Selatan & 4.8 \\
\hline Bengkulu & 10.4 \\
\hline Lampung & 6.0 \\
\hline Bangka Belitung & 10.9 \\
\hline Kepulauan Riau & 10.7 \\
\hline Jakarta & 8.2 \\
\hline Jawa Barat & 10.9 \\
\hline Jawa Tengah & 9.8 \\
\hline Yogyakarta & 10.7 \\
\hline Jawa Timur & 5.9 \\
\hline Banten & 7.7 \\
\hline Bali & 6.9 \\
\hline Nusa Tenggara Barat & 2.9 \\
\hline Nusa Tenggara Timur & 5.7 \\
\hline Kalimantan Barat & 2.8 \\
\hline Kalimantan Tengah & 5.5 \\
\hline Kalimantan Selatan & 7.0 \\
\hline Kalimantan Timur & 10.4 \\
\hline Sulawesi Utara & 11.1 \\
\hline Sulawesi Tengah & 11.9 \\
\hline Sulawesi Selatan & 10.5 \\
\hline Sulawesi Tenggara & 6.9 \\
\hline Gorontalo & 8.6 \\
\hline Sulawesi Barat & 5.0 \\
\hline Maluku & 6.8 \\
\hline Maluku Utara & 4.0 \\
\hline Papua Barat & 8.1 \\
\hline Papua & 2.9 \\
\hline
\end{tabular}

Sumber : Data primer, 2017 
Tabel 2.Hasil Analisis Univariat

\begin{tabular}{|c|c|}
\hline Karakteristik Responden & Distribusi (\%) \\
\hline \multicolumn{2}{|l|}{ Niat Kehamilan } \\
\hline Kehamilan Tidak Diinginkan & 8.0 \\
\hline Kehamilan Tidak Direncanakan & 7.0 \\
\hline Kehamilan Yang Diinginkan & 85.0 \\
\hline \multicolumn{2}{|l|}{ Paritas } \\
\hline$\geq 5$ & 6.3 \\
\hline 4 & 7.2 \\
\hline 3 & 16.1 \\
\hline 2 & 32.4 \\
\hline 1 & 38 \\
\hline \multicolumn{2}{|l|}{ Wilayah Tempat Tinggal } \\
\hline Desa & 49.5 \\
\hline Kota & 50.5 \\
\hline \multicolumn{2}{|l|}{ Status Pernikahan } \\
\hline Tidak Menikah & 2.9 \\
\hline Menikah & 97.1 \\
\hline \multicolumn{2}{|l|}{ Tingkat Pendidikan } \\
\hline Tidak Tamat SD & 8.2 \\
\hline Tamat SD & 24.2 \\
\hline Tidak Tamat SMA & 27.8 \\
\hline Tamat SMA & 27.9 \\
\hline Perguruan Tinggi & 11.9 \\
\hline \multicolumn{2}{|l|}{ Tingkat Ekonomi } \\
\hline Sangat Miskin & 19.0 \\
\hline Miskin & 19.8 \\
\hline Pertengahan & 20.4 \\
\hline Kaya & 21.7 \\
\hline Sangat Kaya & 19.1 \\
\hline \multicolumn{2}{|l|}{ Jarak Kelahiran } \\
\hline 0 bulan (anak pertama) & 38.9 \\
\hline$\leq 36$ bulan & 14.3 \\
\hline $37-72$ bulan & 21.6 \\
\hline$>72$ bulan & 25.2 \\
\hline \multicolumn{2}{|l|}{ Usia } \\
\hline 12-20 tahun & 16.4 \\
\hline 21-29 tahun & 49.8 \\
\hline 30-35 tahun & 31.9 \\
\hline 36-48 tahun & 10.9 \\
\hline
\end{tabular}

Sumber : Data primer, 2017 
Table 3.Hasil Analisis Bivariat

\begin{tabular}{|c|c|c|c|}
\hline Variabel & Kategori & Proporsi (\%) & IK (95\%) \\
\hline \multirow[t]{3}{*}{ Usia } & 21-29 tahun & 3,2 & $.132-.408$ \\
\hline & 30-39 tahun & 14,8 & $.026-.077$ \\
\hline & 40-49 tahun & 36,9 & $.007-.024$ \\
\hline \multirow[t]{3}{*}{ Paritas } & $>4$ anak & 26,5 & $.004-.013$ \\
\hline & 3 anak & 14,2 & $.009-.027$ \\
\hline & 2 anak & 2,5 & $.058-.178$ \\
\hline Wilayah Tempat Tinggal & Kota & 8,9 & $.624-.803$ \\
\hline Status Pernikahan & Menikah & 7,9 & $.057-.334$ \\
\hline \multirow[t]{4}{*}{ Tingkat Ekonomi } & Miskin & 8,3 & $.633-.921$ \\
\hline & Pertengahan & 8,0 & $.655-.964$ \\
\hline & Kaya & 7,8 & $.673-.999$ \\
\hline & Sangat kaya & 8,1 & $.642-.963$ \\
\hline \multirow[t]{7}{*}{ Jarak Lahir } & $1-12$ bulan & 12,2 & $.027-.013$ \\
\hline & 13-24 bulan & 13,3 & $.029-.019$ \\
\hline & 25-36 bulan & 12,9 & $.032-.021$ \\
\hline & $37-48$ bulan & 11,1 & $.041-.027$ \\
\hline & $49-60$ bulan & 9,7 & $.049-.032$ \\
\hline & $61-72$ bulan & 10,0 & $.048-.031$ \\
\hline & $>72$ bulan & 12,0 & $.041-.028$ \\
\hline \multirow[t]{4}{*}{ Tingkat Pendidikan } & Tidak tamat SD & 9,8 & $.555-.424$ \\
\hline & Tamat SD & 8,3 & $.663-.523$ \\
\hline & Tidak tamat SMA & 8,0 & $.679-.538$ \\
\hline & Tamat SMA & 7,0 & $.780-.618$ \\
\hline
\end{tabular}

Sumber : Data primer, 2017

Tabel 4.Ringkasan Hasil Bivariat

\begin{tabular}{lc}
\hline Variable & Nilai $\mathrm{p}$ \\
\hline Usia & .000 \\
Paritas & .000 \\
Wilayah Tempat Tinggal & .000 \\
Status Pernikahan & .000 \\
Tingkat Ekonomi & .041 \\
Jarak Lahir & .000 \\
Tingkat Pendidikan & .000 \\
\hline
\end{tabular}

Sumber : Data primer, 2017 
Tabel 5. Hasil Analisis Multivariat

\begin{tabular}{|c|c|c|c|c|c|c|}
\hline \multirow[b]{2}{*}{ Variabel } & \multirow[b]{2}{*}{ Kategori } & \multirow[b]{2}{*}{ B } & \multirow[b]{2}{*}{$\mathrm{P}$} & \multirow[b]{2}{*}{ OR } & \multicolumn{2}{|c|}{ 95\% C.I.for EXP(B) } \\
\hline & & & & & Min & Max \\
\hline \multirow[t]{3}{*}{ Usia } & 21-29 tahun & .193 & .558 & 1.212 & .636 & 2.310 \\
\hline & 30-39 tahun & -.338 & .315 & .713 & .368 & 1.380 \\
\hline & 40-49 tahun & -1.213 & .001 & .297 & .147 & .601 \\
\hline \multirow[t]{3}{*}{ Paritas } & $\geq 4$ & -4.529 & .000 & .011 & .004 & .026 \\
\hline & 3 & -3.921 & .000 & .020 & .008 & .048 \\
\hline & 2 & -2.222 & .000 & .108 & .044 & .265 \\
\hline Wilayah Tempat Tinggal & Kota & -.412 & .000 & .663 & .562 & .782 \\
\hline \multirow[t]{4}{*}{ Pendidikan } & Tidak tamat SD & -.011 & .950 & .989 & .695 & 1.407 \\
\hline & Tamat SD & -.147 & .360 & .863 & .630 & 1.183 \\
\hline & $\begin{array}{l}\text { Tidak tamat } \\
\text { SMA }\end{array}$ & -.421 & .006 & .656 & .486 & .886 \\
\hline & Tamat SMA & -.145 & .323 & .865 & .650 & 1.153 \\
\hline Status Pernikahan & Menikah & 1.492 & .006 & 4.447 & 1.544 & 12.809 \\
\hline \multirow[t]{7}{*}{ Jarak Lahir } & $1-12$ bulan & -.873 & .065 & .418 & .165 & 1.057 \\
\hline & $13-24$ bulan & -.599 & .069 & .549 & .288 & 1.049 \\
\hline & $25-36$ bulan & -.317 & .332 & .728 & .384 & 1.381 \\
\hline & $37-48$ bulan & -.208 & .527 & .812 & .426 & 1.548 \\
\hline & 49 - 60 bulan & -.017 & .959 & .983 & .512 & 1.886 \\
\hline & $61-72$ bulan & .018 & .957 & 1.018 & .528 & 1.963 \\
\hline & $>72$ bulan & -.003 & .993 & .997 & .532 & 1.870 \\
\hline \multirow[t]{4}{*}{ Tingkat ekonomi } & Miskin & -.477 & .000 & .621 & .498 & .774 \\
\hline & Pertengahan & -.447 & .000 & .640 & .504 & .812 \\
\hline & Kaya & -.450 & .001 & .638 & .494 & .824 \\
\hline & Sangat Kaya & -.421 & .003 & .656 & .495 & .870 \\
\hline
\end{tabular}

Sumber : Data primer, 2017 